\title{
A Model for Optimizing the Structure of Teaching Techniques for Distance Learning in the Russian Higher Education System
}

\author{
Zhanna Gardanova ${ }^{1}$, Vadim Ponkratov ${ }^{2, *}$, Nikolay Kuznetsov ${ }^{3}$, Natalya Nikitina ${ }^{4}$, \\ Olesya Dudnik ${ }^{5}$, Endzhe Latypova ${ }^{6}$ and Sergey Shcherbatykh ${ }^{7}$ \\ 1 Department of Psychotherapy, Pirogov Russian National Research Medical University, 1 Ostrovityanova St., \\ 117997 Moscow, Russia; gardanova58@bk.ru \\ 2 Department of Public Finance, Financial University under the Government of the Russian Federation, \\ 49 Leningradsky Av., 125993 Moscow, Russia \\ 3 Institute of Digital Transformation Management, State University of Management, 99 Ryazansky Av., \\ 109542 Moscow, Russia; nikolay.kuznetsov53@gmail.com \\ 4 Research Institute for Advanced Directions and Technologies, Interdisciplinary Research Laboratory, \\ Russian State Social University, 4 Wilhelm Pieck St., bld. 1, 129226 Moscow, Russia; \\ n.nikitina_info@yahoo.com \\ 5 Department of Pediatric Dentistry and Orthodontics, I.M. Sechenov First Moscow State Medical \\ University (Sechenov University), 8-2 Trubetskaya str., 119991 Moscow, Russia; Olesya.V.Dudnik@yandex.ru \\ 6 Educational Center of Applied Psychology, Ethnopsychology and Intercultural Communication, \\ Kazan Federal University, 18 Kremlyovskaya St., 420008 Kazan, Russia; endzhe.latypova@yandex.ru \\ 7 Rectorate, Bunin Yelets State University, 28 Kommunarov St., 399770 Yelets, Russia; \\ scherbatych2017@yandex.ru \\ * Correspondence: ponkratovvadim@yandex.ru
}

Received: 27 October 2020; Accepted: 12 November 2020; Published: 13 November 2020

\begin{abstract}
This study aims to develop a methodical approach to optimize the structure of teaching techniques and approaches to distance education, as exemplified by Russian universities, to enhance students' professional competencies. A pedagogical experiment was conducted with the participation of 746 second to fourth year students majoring in engineering at the Ural Federal University in Russia. The coefficients for the relative importance of professional competencies were obtained through expert assessment. The number of experts was 40 faculty members with teaching experience of more than five years. The pedagogical experiment revealed the regularities of the influence of the forms of distance learning on the formation of students' professional competency levels. The values of students' developmental competency levels have been determined. Non-linear regression models have been developed based on the values of the integral level of professional competencies and the percentage of distance-learning forms in the number of instructional hours. The proposed methodological approach will be useful for university professors and teachers in identifying the most effective forms of distance learning and in differentiating teaching methods not only in the context of the general pandemic but also in the natural conditions of the educational process.
\end{abstract}

Keywords: distance learning; higher education; students; professional competencies; pandemic; COVID-19

\section{Introduction}

The development of distance education has been recognized as one of the key areas of the primary education programs in the world, including Education for All [1], Learning throughout Life [2], and Education without Borders [3]. Distance learning, also called "distance education", 
is a form of learning in which a teacher and a student interact at a distance, implemented using telecommunication technologies $[4,5]$. Distance learning provides for the interactivity of the learning process [6]. This method of learning is established by using technologies that allow student-teacher interaction, although they occur in different physical environments and timelines. Undoubtedly, the main driver of distance learning has become the development of computer technology, as well as a breakthrough in communication technologies. In addition, this form of education is characterized by a number of advantages over its traditional types: the relative cheapness and availability of education for a large number of people [7].

It is not breaking news anymore that in some circumstances distance education outperforms classroom-based education. In 2018, the results of a study [8] illustrated that $85 \%$ of students who had been enrolled in both an online- and classroom-based course felt their online course experience was either as good as or better than attending their course on campus. According to a past study [9], distance learning provides flexibility in education, which manifests itself in intensification of the educational process; improvement of information and resource provision of training; solving the problem of distance between student and teacher. Distance learning is an integral part of tertiary study in many countries of the world [10,11].

In Russia, also in the last decade, information educational technologies have received intensive, but gradual, development, especially recently in the framework of the National Education Project [12]. However, it should be noted that the coronavirus pandemic forced Russian universities to urgently and completely switch to distance learning [13]. Due to the spread of the COVID-19 pandemic and the introduction of social distancing requirements, students were forced to officially go on vacation from March 28 to April 5, and on April 6 they resumed classes, but at this time in the online mode [14]. The distance-learning mode has been extended until 11 May 2020 in Russian universities because of the coronavirus spread [15]. However, current circumstances can be called urgent delivery of content to listeners in conditions of self-isolation. The transition of the educational process to online mode took place too suddenly, and the universities had to transfer the disciplines designed for full-time teaching to e-learning with minimal adjustments. How effective and painless was this transition? According to the monitoring of highly qualified scientific personnel for 2019 according to the official data of the Institute for Statistical Studies and Economics of Knowledge at the Higher School of Economics (HSE, Moscow, Russia) [16], in the last three years, a quarter (24.3\%) of university employees holding a degree have never carried out educational or scientific events remotely or by video link and did not participate in them. On average, degree-holders teaching at universities rated their level of skills necessary for distance work as 3.2 by a 5 -point scale [16]. Most universities and faculty members themselves were not ready for the transition to the online mode. Even the leading universities of the world were not ready for such a situation in the most developed countries. Studies show that more than $50 \%$ of teachers in the UK and many other countries were not able to organize a distance lesson on their own [17].

The lesson that is important to learn from the COVID-19 situation is similar to the one we observed during previous pandemics-preparedness is a decisive factor. In Russia, as far back as December 2018, the issue of introducing the term "Internet education" into the legislative framework was considered along with the procedure for licensing it [18]. Today, about $40 \%$ of Russian universities are not able to provide remote access to learning resources for students [19], and 70\% of faculty members have no idea how to organize this work [19].

It turned out that the Russian higher education system is not ready for quarantine, not only because of the lack of a sufficient number of sites that can withstand the massive transition to distance education, but mainly because of the lack of online learning models. In particular, a lot of problems are associated with the teaching methodology, which significantly reduces the effectiveness of the educational process and the level of formedness of students' professional competencies. As shown by the practice of distance learning during quarantine at Russian universities, only $5-10 \%$ of students immediately absorb the course content, while the rest ask their teachers a lot of questions in the chat. As a rule, students do not ask so many additional questions at in-person seminars and lectures [16]. 
On the other hand, students complain that their teachers have significantly increased the workload for independent study when switching to distance learning: they record and send lectures without additional explanations of the most difficult aspects, and students have to look for answers on their own, without access to the necessary literature [19].

In the absence of the ability to resolve these current problems at the soonest, the hard-won gains in expanding access to education may stall or reverse, as universities close and alternative options, such as quality distance learning, are not available to everyone. This can lead to the loss of human capital and the reduction in economic opportunities in the country.

Today, scholars and analysts are developing various scenarios for the development of the epidemic [20-24]. Some of them suggest that the spread of COVID-19 will occur in waves [21-24], which means that the process of combating it must be cyclical. That is, current conditions dictate the requirements of constant readiness of the higher education system in case of quarantine and self-isolation to be able to provide high-quality continuing education to students of Russian universities without wasting time and unnecessary resources through effective distance-teaching techniques.

Many scientists [25], within the framework of their research, have testified that, with the correct organization and an effective approach, distance learning can be no less effective than traditional teaching methods. The remote form allows for working with the best teachers, according to the most perfect program, to achieve high results even without being on the territory of the educational institution. Of course, in this matter, much depends on the student: on their ability to organize the process and master the material. However, for distance learning, forms of control are provided that are similar to full-time, it is possible to attend certain classes or sessions in person [26]. However, it should be noted that the lack of personal contact between the teacher and the student often determines the insufficient level of student performance [27]. Personal constant interaction and feedback from the teacher significantly increases the actual control over the development of the material, gives an additional opportunity to help the student, and allows for studying the topic of interest deeper. The totality of teaching methods and techniques used in the educational process is an important integrated factor in the effectiveness of the formation of students' professional competencies in the process of distance learning is. The aim of the study was to develop a methodological approach to optimizing the structure of pedagogical methods and approaches of distance learning using the example of Russian universities to increase the level of formation of students' professional competencies. The research is based on the hypothesis that the most effective from the standpoint of mastering professional competencies are audio-visual forms of distance learning, which, unlike traditional forms such as text lectures and computational tasks, minimize the lack of "live" contact between the teacher and the student (hypothesis H1). Presumably, the highest efficiency of audiovisual forms of distance learning is explained by the teacher's ability to increase the interest of students and focus on important aspects of the topic being studied. At the same time, the importance of using traditional forms is due to their greater information content (text lectures) and practical orientation (creative, situational, computational tasks) - the hypothesis H2. The maximum effectiveness of distance learning is achieved when all forms of education are combined (hypothesis H3). Therefore, this article posed the following tasks of scientific research: to reveal the features and nature of the influence of the main distance-education forms (video lessons; audio lessons; text lecture; creative tasks with examples; computational tasks with examples, as well as cases and situational tasks for the development of students' professional competencies; to determine the quantitative and qualitative levels of students' professional competencies formation and to justify the most effective structure of teaching techniques for distance learning, which provides the enhancement of the integral level of students' professional competencies). 


\section{Materials and Methods}

\subsection{Research Base}

The study was conducted at the Ural Federal University in Ekaterinburg, Russia. Its use as a research base is due to the fact that this university has created conditions for the implementation of the experiment. Even before the quarantine period and the prerequisite for the transition to distance learning, the university had an electronic platform for organizing distance learning; online courses of the university and partner universities, electronic textbooks, and teaching aids were used. The presence of appropriate conditions simplified the implementation of the experiment and made it possible to maximally demonstrate the influence of forms of distance learning on its effectiveness, avoiding the influence of such factors as the inexperience of teachers in the field of organizing distance learning, low-quality educational online content, lack of access to online courses, and students' misunderstanding of the mechanism of distance learning.

This study assumed an experiment in the course of distance learning aimed at identifying the nature of the impact exerted by the distance-education forms on the effectiveness of the learning process. The experiment was conducted from September to December 2019 and from February to April 2020 with the participation of the full-time second-fourth year students of technical specialties (Power Engineering and Electrical Engineering, Mechanics and Mathematical Modeling, Technological Machines and Equipment), while studying the following disciplines: Theoretical Foundations of Electrical Engineering, Electric Machines in the Electrical Power-Generation Industry, Protection and Automation of Electrical Power Systems, Theoretical and Applied Mechanics, Stability Theory, Theoretical Mechanics, and Metallurgical Machines and Equipment. The participation of the students of various undergraduate courses and specialties in the experiment revealed the universal and distinctive features of the effectiveness of distance learning at the university based on the management of the implementation intensity of various distance-education forms.

The experiment was attended by 746 students with different levels of performance, who were warned about participating in the experiment and gave their written consent to take part in it. The number of participants indicates the representativeness of the research results. The experiment did not imply the formation of students' assessments regarding the effectiveness of distance education; therefore, the objectivity of the results can be claimed. Ensuring the confidentiality of the research results provided the observance of ethical standards during the experiment.

\subsection{The Conditions of the Pedagogical Experiment}

The experiment was aimed at enhancing the effectiveness of distance learning by optimizing the ratio of presentation forms, such as video lessons (A), audio lessons (B), text lectures (C), creative tasks with examples (D), computational tasks with examples (E), and cases with situational tasks (F). Only those forms of training aimed at offering new knowledge or skills were examined, while those aimed at assessing knowledge, such as tests, were not considered. In this study, distance learning is understood to be of the asynchronous variety, which has become widespread due to common teacher-student differences (the COVID-19 pandemic has acutely illustrated the need for increasing the effectiveness of distance learning as many students are now living in different time zones). Differences in the Internet connection speed can also significantly reduce the quality and accessibility of learning material further discouraging the use of more synchronous distance-education methods. Therefore, to exclude factors outside the educational sphere, the experiment only examined the effectiveness of distance learning that is asynchronous.

The experiment was carried out in two stages:

1. It was conducted first from September to December 2019 and February to March 2020 (before the introduction of the quarantine) and regarded training in the specialties of Mathematical Modeling, Technological Machines, and Equipment, while studying the disciplines: Theoretical Foundations of Electrical Engineering, Electric Machines in the Electrical Power-Generation 
Industry, Protection and Automation of Electrical Power Systems, Theoretical and Applied Mechanics, Stability Theory, Theoretical Mechanics, and Metallurgical Machines and Equipment when distance learning was introduced as a pilot project. At this stage, $20 \%$ of the total number of students majoring in Power Engineering and Electrical Engineering, Mechanics and Mathematical Modeling, and Technological Machines and Equipment took part in the experiment. These students studied remotely, though their knowledge control was carried out in a classroom environment. Students who did not participate in the experiment studied without changes in the educational process and the discipline structure

2. The experiment then continued from March to April 2020 (during the quarantine period), when distance learning was mandatory. During this stage, all students who studied the indicated disciplines took part in the experiment

The change in the number of the participants in the experiment is due to the changes in the objective teaching conditions associated with the COVID-19 pandemic when universities switched to distance learning due to the quarantine. Therefore, all students of relevant specialties and disciplines took part in the experiment. This allowed for the expansion of the research sample, thus increasing the accuracy of the experiment results. Before the quarantine, the involvement of all students in the experiment was impossible due to the need to make changes in the educational process. Within the stages, the number of the students remained unchanged.

Statistically, the possibility of using different numbers during these stages is confirmed by the $\mathrm{t}$-criterion. The empirical values of the $\mathrm{t}$-criterion proved the absence of statistically significant differences in the obtained results of the experiment at the 1st and 2nd stages.

The selection of disciplines for the experiment was determined by their study durations-taking two semesters for students of the same course to provide the time necessary to simulate various options for combining distance learning approaches. The experiment schedule was formed based on a random combination of the distance-education forms in compliance with the following principles:

1. The sum of the percentages $(\Sigma \rho)$ used during a week of the distance-education forms (A-F), expressed in fractions of the total number of hours allocated to the discipline for the week, equals 1.0.

2. Provision is made for different combinations of the distance-education forms during a week $(\mathrm{A}+\mathrm{B}, \mathrm{A}+\mathrm{C}, \mathrm{A}+\mathrm{D}, \mathrm{A}+\mathrm{E}, \mathrm{A}+\mathrm{F}, \mathrm{B}+\mathrm{C}, \mathrm{B}+\mathrm{D}, \mathrm{B}+\mathrm{E}, \mathrm{B}+\mathrm{F}, \mathrm{C}+\mathrm{D}, \mathrm{C}+\mathrm{E}, \mathrm{C}+\mathrm{F}, \mathrm{D}+\mathrm{E}, \mathrm{D}+\mathrm{F}, \mathrm{E}+\mathrm{F})$.

3. For each distance-education form, $\rho=[0.1 ; 0.9]$ in increments of 0.1 .

An example of the experiment schedule for the discipline Theoretical and Applied Mechanics (for the third year students majoring in Mechanics and Mathematical Modeling) is given in Table 1.

The initial condition for the implementation of the pedagogical experiment at week 1 in this discipline was the following distribution of the distance-education forms: $\rho 1 \mathrm{~A}=0.9, \rho 1 \mathrm{~B}=0, \rho 1 \mathrm{C}=0.1$, $\rho 1 \mathrm{D}=0, \rho 1 \mathrm{E}=0, \rho 1 \mathrm{~F}=0$, where $\rho \mathrm{A}$ is a percentage of video lessons (expressed in shares) of the total number of hours allocated to the discipline for the working week, $\rho \mathrm{B}$-a percentage of audio lessons from the total number of hours allocated to the discipline for the working week, $\rho \mathrm{C}$-a percentage of text lectures from the total number of hours allocated to discipline for the working week, $\rho \mathrm{D}$-a percentage of creative tasks from the total number of hours assigned to the discipline for the working week, $\rho \mathrm{E}$-a percentage of computational tasks from the total number of hours allocated to the discipline for the working week, and $\rho \mathrm{F}$ is a percentage of situational tasks from the total number of hours allocated to the discipline for the working week. 
Table 1. Schedule for experimenting to improve the distance learning effectiveness at the university: a case study of learning the discipline "Theoretical and Applied Mechanics".

\begin{tabular}{|c|c|c|c|c|c|c|c|}
\hline \multirow{2}{*}{$\begin{array}{l}\text { Indexing Number of the } \\
\text { Experiment Week }\end{array}$} & \multicolumn{6}{|c|}{ Percentage of the Distance-Education Forms $(\rho)$} & \multirow{2}{*}{$\Sigma \rho$} \\
\hline & A & B & $C$ & D & E & $\mathbf{F}$ & \\
\hline 1 & 0.9 & - & 0.1 & - & - & - & 1 \\
\hline 2 & 0.8 & - & - & 0.2 & - & - & 1 \\
\hline 3 & 0.7 & 0.3 & - & - & - & - & 1 \\
\hline 4 & 0.6 & - & - & - & 0.4 & - & 1 \\
\hline 5 & 0.5 & - & - & - & - & 0.5 & 1 \\
\hline 6 & 0.4 & 0.6 & - & - & - & - & 1 \\
\hline 7 & 0.3 & - & 0.7 & - & - & - & 1 \\
\hline 8 & 0.2 & - & - & 0.8 & - & - & 1 \\
\hline 9 & 0.1 & - & - & - & 0.9 & - & 1 \\
\hline 10 & - & - & 0.3 & 0.7 & - & - & 1 \\
\hline 11 & - & - & 0.4 & 0.6 & - & - & 1 \\
\hline 12 & - & - & 0.5 & 0.5 & - & - & 1 \\
\hline 13 & - & - & 0.6 & - & - & 0.4 & 1 \\
\hline 14 & - & 0.7 & - & 0.3 & - & - & 1 \\
\hline 15 & - & 0.2 & 0.8 & - & - & - & 1 \\
\hline 16 & - & - & 0.9 & - & 0.1 & - & 1 \\
\hline 17 & - & 0.8 & - & - & 0.2 & - & 1 \\
\hline 18 & - & - & - & 0.9 & - & 0.1 & 1 \\
\hline 19 & - & - & - & - & 0.3 & 0.7 & 1 \\
\hline 20 & - & 0.4 & - & - & - & 0.6 & 1 \\
\hline 21 & - & 0.5 & - & - & 0.5 & - & 1 \\
\hline 22 & - & - & - & 0.4 & 0.6 & - & 1 \\
\hline 23 & - & - & - & - & 0.7 & 0.3 & 1 \\
\hline 24 & - & - & - & - & 0.8 & 0.2 & 1 \\
\hline 25 & - & 0.9 & - & 0.1 & - & - & 1 \\
\hline 26 & - & 0.1 & - & - & - & 0.9 & 1 \\
\hline 27 & - & - & 0.2 & - & - & 0.8 & 1 \\
\hline
\end{tabular}

Note: A-F-forms of distance education; A—video lessons; B-audio lessons; C-text lectures; D—creative tasks with examples; E-computational tasks with examples; $\mathrm{F}$ - cases and situational tasks; $\rho$ - the percentage of the distance-education form (A-F), expressed in fractions of the total number of hours allocated to the discipline for the working week; $\Sigma \rho$-a sum of percentages used during a week of the distance-education forms (A-F).

At week 2, the value of the indicators (experiment parameters) was $\rho 2 \mathrm{~A}=0.8, \rho 2 \mathrm{~B}=0, \rho 2 \mathrm{C}=0$, $\rho 2 \mathrm{D}=0.2, \rho 2 \mathrm{E}=0, \rho 2 \mathrm{~F}=0$, etc. The sum of the specific weights used during the week of using distance learning forms is 1 for each week. During the training period, the percentage combination of the distance learning forms was not repeated.

In the initial version, all the hours allocated to the discipline study (classroom and extracurricular) were distributed between video lessons (90\%) and text lectures (10\%). In the second week of the experiment, working time was allocated to video lessons $(80 \%)$ and creative tasks with examples $(20 \%)$, etc. At the same time, the number of weeks devoted to the disciplined study, the competence to master, at which the discipline was aimed, the training program results corresponded to the work program. The course topics, their sequence, and the number of the hours devoted to each course were also in line with the work program. That is, the experiment was aimed at changing the structure of the teaching forms (the values of the indicators $\rho \mathrm{A}-\rho \mathrm{F}$, their dynamics, and correlation), without changing the content. To ensure the experiment purity, the subject teacher remained the same throughout the working weeks and no unauthorized persons (stakeholders, consultants, other instructors) were involved in teaching the subjects.

The experiment schedules in other disciplines are similar, but with a different ratio of $\rho \mathrm{A}-\rho \mathrm{F}$ indicators during a week (with a purpose to maximize tracking of the possible combinations of the distance-education forms) and different dynamics of $\rho \mathrm{A}-\rho \mathrm{F}$ indicators (ascending/descending) during the experiment period (aimed to exclude the influence of the week of study and the topic of discipline on 
the effectiveness of the distance-education forms). The schedules of the experiment in other disciplines are given in the section "Appendix A".

\subsection{Assessment of Students' Competency Based on the Results of Distance Learning}

The effectiveness of distance learning was assessed from the position of a competency-based approach for such components of integral technical expertise as constructive-computational (Comp_1), diagnostic-designing (Comp_2), communicative-managerial (Comp_3), and constructive-creative competencies (Comp_4), which are key for students of technical specialties [28-30]. The current control was aimed at assessing the level of competency formedness, by solving:

1. Written tests and computational tasks aimed at assessing the level of constructive-computational competency (Comp_1), which characterizes the ability to analytical activity.

2. Diagnostic tasks aimed at assessing the level of diagnostic-designing competency (Comp_2), which characterizes the ability to develop strategic concepts and business projects and assess the quality and effectiveness of projects.

3. Situational tasks of a managerial nature, aimed at assessing the level of communicative-managerial competency (Comp_3), which characterizes the ability to manage, coordinate, and control the implementation of projects.

4. Creative tasks aimed at assessing the level of constructive-creative competency (Comp_4), which characterizes the ability to scientific activity, development, and improvement of methods and tools of professional activity.

All tasks had the same level of difficulty.

Each component of the integral competency was assessed by the teacher by the results of solving the task on a 10-point scale, where:

- " 0 " points meant that the task was not solved, no definitions, formulas, ideas concerning this task were given.

- " $1-2$ " points- the task was not solved, but the basic concepts and formulas necessary for the solution were given.

- " $3-4$ " points- basic concepts and formulas necessary for the solution were given, the algorithm for solving the problem was correctly defined, but there were significant errors in the computations, which made it impossible to get the correct result.

- " $5-6$ " points-insignificant errors were made when solving the task.

- "7-9" points— the task was solved correctly, but there were no corresponding argumentation, justification, or conclusions.

- " 10 " points-the task was solved correctly; the decision and conclusions were reasoned and justified.

Test tasks were evaluated in proportion to the number of correct answers and the complexity of the tasks.

Within the framework of this study, the assessment of students' competencies was carried out by the teacher. With his consent, the results were submitted for statistical processing to the authors of the article in anonymity. In similar studies, the assessment of students' competencies can be carried out by the researcher, if the teacher is competent in the relevant academic disciplines, especially created by a competent independent expert group or a separate expert. In this case, a tool for collecting data can be a questionnaire survey by means of students' e-mails, personal accounts on online platforms for distance learning, Google Forms, or other similar means of remote information exchange.

The assessments of the Comp_1-Comp_4 competency formedness obtained during this study were transferred into levels to obtain a balanced, integrated assessment to align the possibility of obtaining an average assessment. Student's t-test was used to determine the levels, which made it possible to delimit the scores of students' competencies having statistically significant differences. 
These ranges of values formed the levels of $100 \%$ probability of classifying the $i$-th competency score as low, medium, and high. The levels of intermediate values of competencies were determined in terms of the trapezoidal membership function. The constructed competency levels take the form:

$$
\begin{aligned}
& \mu_{1}=\left\{\begin{array}{l}
1,0 \leq \operatorname{Comp}_{i} \leq \operatorname{Comp}_{i}\left(t_{1}\right) \\
\frac{\operatorname{Comp}_{i}\left(t_{2}\right)-\operatorname{Comp}_{i}}{\operatorname{Comp}_{i}\left(t_{2}\right)-\operatorname{Comp}_{i}\left(t_{1}\right)}, \operatorname{Comp}_{i}\left(t_{1}\right)<\operatorname{Comp}_{i}<\operatorname{Comp}_{i}\left(t_{2}\right) \\
0, \operatorname{Comp}_{i}\left(t_{2}\right) \leq \operatorname{Comp}_{i} \leq 10
\end{array}\right. \\
& \mu_{2}=\left\{\begin{array}{l}
0,0 \leq \operatorname{Comp}_{i} \leq \operatorname{Comp}_{i}\left(t_{1}\right) \\
\frac{\operatorname{Comp}_{i}-\operatorname{Comp}_{i}\left(t_{1}\right)}{\operatorname{Comp}_{i}\left(t_{2}\right)-\operatorname{Comp}_{i}\left(t_{1}\right)}, \operatorname{Comp}_{i}\left(t_{1}\right)<\operatorname{Comp}_{i}<\operatorname{Comp}_{i}\left(t_{2}\right) \\
1, \operatorname{Comp}_{i}\left(t_{2}\right) \leq \operatorname{Comp}_{i} \leq \operatorname{Comp}_{i}\left(t_{3}\right) \\
\frac{\operatorname{Comp}_{i}\left(t_{4}\right)-\operatorname{Comp}_{i}}{\operatorname{Comp}_{i}\left(t_{4}\right)-\operatorname{Comp}_{i}\left(t_{3}\right)}, \operatorname{Comp}_{i}\left(t_{3}\right)<\operatorname{Comp}_{i}<\operatorname{Comp}_{i}\left(t_{4}\right) \\
0, \operatorname{Comp}_{i}\left(t_{4}\right) \leq \operatorname{Comp}_{i} \leq 10
\end{array}\right. \\
& \mu_{3}=\left\{\begin{array}{l}
0,0 \leq \operatorname{Comp}_{i} \leq \operatorname{Comp}_{i}\left(t_{3}\right) \\
\frac{\operatorname{Comp}_{i}-\operatorname{Comp}_{i}\left(t_{3}\right)}{\operatorname{Comp}_{i}\left(t_{4}\right)-\operatorname{Comp}_{i}\left(t_{3}\right)}, \operatorname{Comp}_{i}\left(t_{3}\right)<\operatorname{Comp}_{i}<\operatorname{Comp}_{i}\left(t_{4}\right) \\
1, \operatorname{Comp}_{i}\left(t_{4}\right) \leq \operatorname{Comp}_{i} \leq 10
\end{array}\right.
\end{aligned}
$$

where $\mu_{1}$ is the probability of classifying the $i$-th competency score as having a low level, $\mu_{2}$ as having a medium level, and $\mu_{3}$ as having a high level. The number of levels $(m)$ is determined based on differences in the Comp $p_{i}$ values that are statistically significant by the $t$-criterion at $p=0.05$. For all $i=\overline{1,4} m=3$;

Comp $p_{i}$-a score of the $i$-th competence;

[0; $\left.\operatorname{Comp}_{i}\left(t_{1}\right)\right],\left[\operatorname{Comp}_{i}\left(t_{2}\right) ; \operatorname{Comp}_{i}\left(t_{3}\right)\right]$, [Comp $\left.\left(t_{4}\right) ; 10\right]-$ low, medium, and high levels of competencies, respectively, the differences between them are statistically significant by the $t$-criterion.

The upper limit for Comp $i$ at a high level corresponds to the maximum possible score on the assignment for assessing the $i$-th competence. For all competencies, this is 10 points.

The use of fuzzy membership functions made it possible to identify intervals of values that correspond to a certain level $(\mu=1)$ with $100 \%$ probability, as well as uncertainty ranges for which the probability $\mu=[0 ; 1)$. The development of students' competencies is not described by a step function; therefore, there are no exact boundaries of indicators that delineate levels of competencies. The use of fuzzy sets, in this case, allows for a more adequate assessment of the level of students' competencies formed during distance learning.

The relative importance of the Comp_1-Comp_4 competencies in the formation of their integral level was assessed using the expert method. The expert group was formed by teachers of the disciplines involved in the experiment, as well as other teachers of technical disciplines who provide training for students in the specialties "Power Engineering and Electrical Engineering", "Mechanics and Mathematical Modeling", and "Technological Machines and Equipment" at the Ural Federal University. The total number of experts was 40 people. The teaching experience of more than 5 years, professional compliance, and the consistency of expert opinions (coefficient of concordance was 0.81 ) ensured the objectivity and adequacy of the assessment results.

Experts were offered to assess the importance of forming Comp_1-Comp_4 competencies by a point-based assessment on a 5-point scale in the professional development of students majoring in Power Engineering and Electrical Engineering, Mechanics and Mathematical Modeling, and Technological Machines and Equipment.

A rating of " 0 " points corresponded to competency insignificance, " 5 " points determined the highest importance of competency in the students' professional development. 
The integrated assessment of the formed competencies was calculated by the formula:

$$
\text { Int }=\sum_{i=1}^{n} \frac{b_{i}}{\sum_{i=1}^{n} b_{i}} \times q_{i}
$$

where Int is an integrated assessment of the formed competency level, Int $=[0 ; 1]$;

$b_{i}$-scoring of the $i$-th competency importance (average scoring by the expert group);

$\Sigma b_{i}$ - the sum of the average scores of importance for all competencies;

$b_{i} / \Sigma b_{i}$ - the coefficient of the relative importance of the $i$-th competency in the formation of professional competencies of students majoring in technical specialties;

$q_{i}$ - a conditional assessment corresponding to the level of the $i$-th competency. With a low level of the $i$-th competency, $q_{i}=0$, with a medium level- $q_{i}=0.5$, with a high one- $q_{i}=1$. In contrast to [31], $q_{i}$ acquires the lowest possible value of 0 at a low level and a maximum possible value of 1.0 at a high level. This is associated with the fact that at a low level of all competencies $\left(\operatorname{Comp}_{i} \rightarrow 0, i=\overline{1,4}\right)$; the integral professional competency also acquires the value of 0 , with a high level of all competencies $\left(\operatorname{Comp}_{i} \rightarrow 10, i=\overline{1,4}\right)$; integral professional competency is assessed at the maximum score, which is impossible when assessing by analogy with the indicated references. The intermediate value $q_{i}=0.5$ for the medium level is taken as the arithmetic average of the indicator corresponding to low and high levels.

The levels of the integral indicator were determined by analogy with the levels of competencies (Formula (1)), based on the values of the $t$-criterion at $p=0.05$.

\subsection{Simulation of the Effectiveness of Distance Learning}

To build models in assessing the impact of the distance learning structure (percentage of the distance learning forms $\rho \mathrm{A}-\rho \mathrm{F}$ ) on the students' competency level, the nonlinear assessment method was applied in the Statistica 12.0 software program. An integrated assessment of the competency level (Int) was used as a dependent variable of the model, and $\rho \mathrm{A}-\rho \mathrm{F}$ indicators were used as an independent variable. The search for the optimal combination of the $\rho \mathrm{A}-\rho \mathrm{F}$ parameters was carried out according to the criterion Int $\rightarrow$ max, with $\rho \mathrm{A}+\rho \mathrm{B}+\rho \mathrm{C}+\rho \mathrm{D}+\rho \mathrm{E}+\rho \mathrm{F}=1$. The data sample for constructing models made $n=3247$ observations.

\section{Results}

The values of the level of formed competencies in students who took part in the experiment vary in the range $[2 ; 10]$-for constructive-computational competency; [1; 10]—for diagnostic-designing competency; $[1 ; 10]$ —for communicative-managerial competency; and $[1 ; 10]$-for constructive-creative competency. The average ratings made $[6.5 ; 7.8]-$ for constructive-computational competency; [6.5; 7.4]—for diagnostic-designing; [6.3; 7.5]—for communicative-managerial; [6.0; 7.2]—for constructive and creative competencies, depending on the year of study and the discipline (Table 2).

The quarantine introduced in connection with the COVID-19 pandemic (closing of universities) had a significant impact on the educational process at universities, which could significantly affect the results of the experiment. To assess this impact, the sample average values of the level of students' competencies development before the quarantine and during the quarantine period were checked by the $t$-criterion over the entire sample (across all competencies, courses, specialties, and disciplines). The tabular value (1.96) exceeds the empirical one (0.84) at $p=0.05$, indicating the absence of statistically significant differences in the level of students' competencies from September 2019 to 23 March 2020 and from 23 March 2020 until the completion of the experiment. This means that the quarantine did not have a significant impact on the experiment. The generated data sample can be considered homogeneous and may be used in modeling the effectiveness of distance learning. 
Table 2. Average values of the level of the formed students' professional competencies.

\begin{tabular}{ccccccccc}
\hline \multirow{2}{*}{$\begin{array}{c}\text { Year of } \\
\text { Study }\end{array}$} & Competency & \multicolumn{2}{c}{$\begin{array}{c}\text { Power Engineering and } \\
\text { Electrical Engineering }\end{array}$} & $\begin{array}{c}\text { Mechanics and } \\
\text { Mathematical } \\
\text { Modeling }\end{array}$ & $\begin{array}{c}\text { Technological } \\
\text { Machines and } \\
\text { Equipment }\end{array}$ \\
\cline { 3 - 8 } & & D1 & D2 & D3 & D4 & D5 & D6 & D7 \\
\hline \multirow{2}{*}{2} & Comp_1 & 6.8 & - & - & 6.5 & - & 7 & - \\
& Comp_2 & 6.6 & - & - & 6.5 & - & 6.6 & - \\
& Comp_3 & 6.6 & - & - & 6.3 & - & 6.4 & - \\
& Comp_4 & 6.0 & - & - & 6.1 & - & 6.3 & - \\
3 & Comp_1 & - & 7.2 & - & 6.7 & - & - & 7.1 \\
& Comp_2 & - & 6.9 & - & 6.5 & - & - & 6.9 \\
& Comp_3 & - & 6.8 & - & 6.5 & - & - & 6.7 \\
4 & Comp_4 & - & 6.5 & - & 6.3 & - & - & 6.7 \\
& Comp_1 & - & - & 7.5 & - & 7.8 & - & 7.4 \\
& Comp_2 & - & - & 7.4 & - & 7.3 & - & 7.1 \\
& Comp_3 & - & - & 7.4 & - & 7.5 & - & 6.9 \\
\hline
\end{tabular}

Note: Comp_1-Comp_4-technical competencies; D1-D7-disciplines: D1-Theoretical Foundations of Electrical Engineering; D2-Electric Machines in the Electrical Power-Generation Industry; D3-Protection and Automation of Electrical Power Systems; D4-Theoretical and Applied Mechanics; D5-Stability Theory; D6-Theoretical Mechanics; D7-Metallurgical Machines and Equipment.

There are no significant differences in terms of the $t$-criterion or in the average level of competencies depending on the week of the experiment, which makes it possible to build a universal model of the effectiveness of distance learning, regardless of the discipline topic.

The membership functions regarding the levels of technical competencies development that were determined based on the values of the Comp_1-Comp_4 competencies for a sample of the second-fourth year students who took part in the experiment are shown in Figure 1.

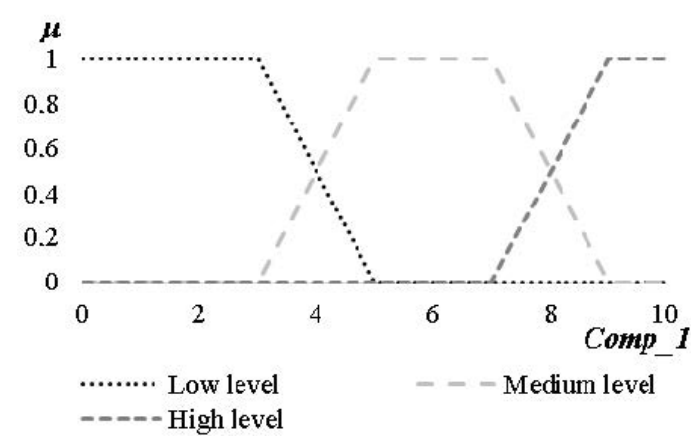

$$
\begin{aligned}
& \mu_{1}=\left\{\begin{array}{l}
1,0 \leq \operatorname{Comp}_{i} \leq 3 \\
\frac{5-\operatorname{Comp}_{i}}{2}, 3<\operatorname{Comp}_{i}<5 \\
0,5 \leq \operatorname{Comp}_{i} \leq 10
\end{array}\right. \\
& \mu_{2}=\left\{\begin{array}{l}
0,0 \leq \operatorname{Comp}_{i} \leq 3 \\
\frac{\operatorname{Comp}_{i}-3}{2}, 3<\operatorname{Comp}_{i}<5 \\
1,5 \leq \operatorname{Comp}_{i} \leq 7 \\
\frac{9-\operatorname{Comp}_{i}}{2}, 7<\operatorname{Comp}_{i}<9 \\
0,9 \leq \operatorname{Comp}_{i} \leq 10
\end{array}\right.
\end{aligned}
$$

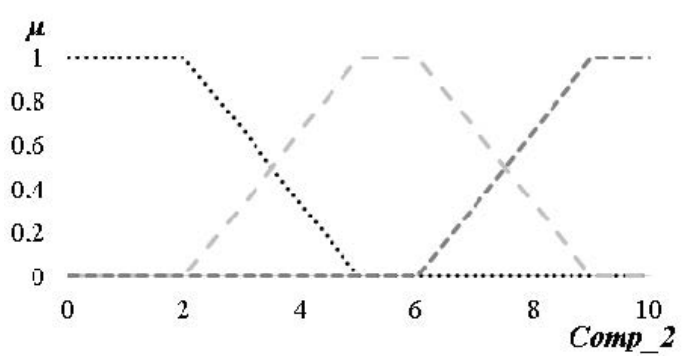

…..... Low level

--- Medium level ----- High level

$$
\begin{aligned}
& \mu_{1}=\left\{\begin{array}{l}
1,0 \leq \operatorname{Comp}_{i} \leq 2 \\
\frac{5-\operatorname{Comp}_{i}}{3}, 2<\operatorname{Comp}_{i}<5 \\
0,5 \leq \operatorname{Comp}_{i} \leq 10
\end{array}\right. \\
& \mu_{2}=\left\{\begin{array}{l}
0,0 \leq \operatorname{Comp}_{i} \leq 2 \\
\frac{\operatorname{Comp}_{i}-2}{3}, 2<\operatorname{Comp}_{i}<5 \\
1,5 \leq \operatorname{Comp}_{i} \leq 6 \\
\frac{9-\operatorname{Comp}_{i}}{3}, 6<\operatorname{Comp}_{i}<9 \\
0,9 \leq \operatorname{Comp}_{i} \leq 10
\end{array}\right.
\end{aligned}
$$

Figure 1. Cont. 


$$
\mu_{3}=\left\{\begin{array}{l}
0,0 \leq \operatorname{Comp}_{i} \leq 7 \\
\frac{\operatorname{Comp}_{i}-7}{2}, 7<\operatorname{Comp}_{i}<9 \\
1,9 \leq \operatorname{Comp}_{i} \leq 10
\end{array}\right.
$$

(a)

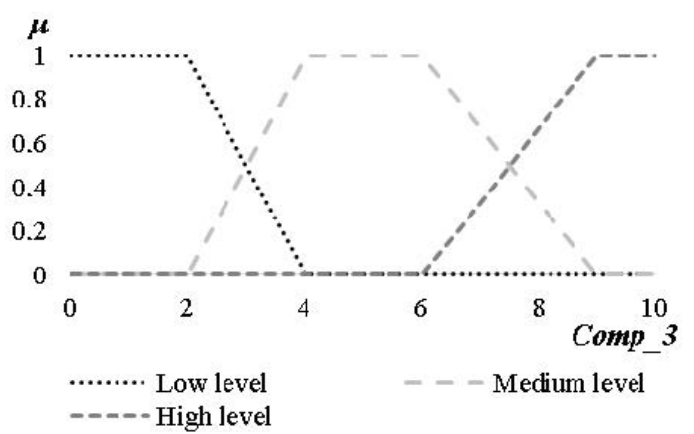

$$
\begin{aligned}
& \mu_{1}=\left\{\begin{array}{l}
1,0 \leq \operatorname{Comp}_{i} \leq 2 \\
\frac{4-\operatorname{Comp}_{i}}{2}, 2<\operatorname{Comp}_{i}<4 \\
0,4 \leq \operatorname{Comp}_{i} \leq 10
\end{array}\right. \\
& \mu_{2}=\left\{\begin{array}{l}
0,0 \leq \operatorname{Comp}_{i} \leq 2 \\
\frac{\operatorname{Comp}_{i}-2}{2}, 2<\operatorname{Comp}_{i}<4 \\
1,4 \leq \operatorname{Comp}_{i} \leq 6 \\
\frac{9-\operatorname{Comp}_{i}}{3}, 6<\operatorname{Comp}_{i}<9 \\
0,9 \leq \operatorname{Comp}_{i} \leq 10
\end{array}\right. \\
& \mu_{3}=\left\{\begin{array}{l}
0,0 \leq \operatorname{Comp}_{i} \leq 6 \\
\frac{\operatorname{Comp}_{i}-6}{3}, 6<\operatorname{Comp}_{i}<9 \\
1,9 \leq \operatorname{Comp}_{i} \leq 10
\end{array}\right.
\end{aligned}
$$

(c) $\mu_{3}=\left\{\begin{array}{l}0,0 \leq \operatorname{Comp}_{i} \leq 6 \\ \frac{\operatorname{Comp}_{i}-6}{3}, 6<\operatorname{Comp}_{i}<9 \\ 1,9 \leq \operatorname{Comp}_{i} \leq 10\end{array}\right.$

(b)

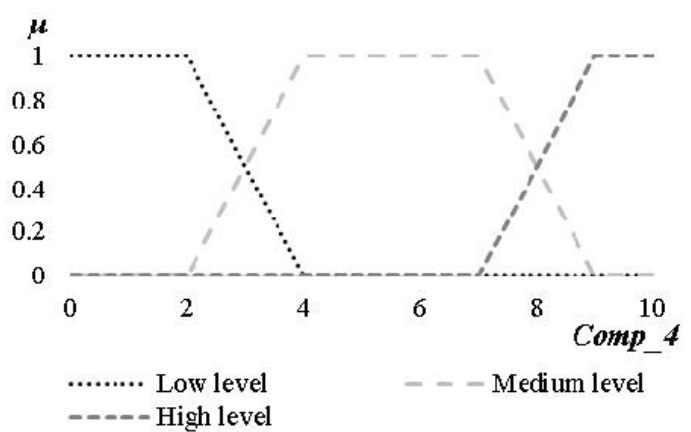

$$
\begin{aligned}
& \mu_{1}=\left\{\begin{array}{l}
1,0 \leq \operatorname{Comp}_{i} \leq 2 \\
\frac{4-\operatorname{Comp}_{i}}{2}, 2<\operatorname{Comp}_{i}<4 \\
0,4 \leq \operatorname{Comp}_{i} \leq 10
\end{array}\right. \\
& \mu_{2}=\left\{\begin{array}{l}
0,0 \leq \operatorname{Comp}_{i} \leq 2 \\
\frac{\operatorname{Comp}_{i}-2}{2}, 2<\operatorname{Comp}_{i}<4 \\
1,4 \leq \operatorname{Comp}_{i} \leq 7 \\
\frac{9-\operatorname{Comp}_{i}}{2}, 7<\operatorname{Comp}_{i}<9 \\
0,9 \leq \operatorname{Comp}_{i} \leq 10
\end{array}\right. \\
& \mu_{3}=\left\{\begin{array}{l}
0,0 \leq \operatorname{Comp}_{i} \leq 7 \\
\frac{\operatorname{Comp}_{i}-7}{2}, 7<\operatorname{Comp}_{i}<9 \\
1,9 \leq \operatorname{Comp}_{i} \leq 10
\end{array}\right.
\end{aligned}
$$

(d)

Figure 1. Membership functions regarding the levels of students' professional competencies development: (a) membership functions regarding the levels of constructive-computational competency development (Comp_1); (b) membership functions regarding the levels of diagnostic-designing competency development (Comp_2); (c) membership functions regarding the levels of communicative-managerial competency development (Comp_3); (d) membership functions regarding the levels of constructive-creative competency development (Comp_4).

The relative importance of the Comp_1-Comp_4 competencies in the formation of professional competencies of students majoring in Engineering was determined by experts at the level of 0.26 for constructive-computational competency; 0.30 for diagnostic-designing competency; 0.20 for communicative-managerial competency; and 0.24 for constructive-creative competency. Taking into account the levels of the Comp_1-Comp_4 competencies and their relative importance based on the Formula (2), the levels of students' integral technical competence were determined: 


$$
\begin{aligned}
& \mu_{1}=\left\{\begin{array}{l}
1,0 \leq \text { Int } \leq 0.15 \\
\frac{0.35-\text { Int }}{0.2}, 0.15<\text { Int }<0.35 \\
0,0.35 \leq \text { Int } \leq 1
\end{array}\right. \\
& \mu_{2}=\left\{\begin{array}{l}
0,0 \leq \text { Int } \leq 0.15 \\
\frac{\operatorname{Int}-0.15}{0.2}, 0.15<\text { Int }<0.35 \\
1,0.35 \leq \text { Int } \leq 0.68 \\
\frac{0.85-\text { Int }}{0.17}, 0.68<\text { Int }<0.85 \\
0,0.85 \leq \text { Int } \leq 1
\end{array}\right. \\
& \mu_{3}=\left\{\begin{array}{l}
0,0 \leq \text { Int } \leq 0.68 \\
\frac{\operatorname{Int}-0.68}{0.17}, 0.68<\text { Int }<0.85 \\
1,0.85 \leq \text { Int } \leq 1
\end{array}\right.
\end{aligned}
$$

where $\mu_{1}$ is a probability of assigning the integral competency value to a low level, $\mu_{2}$ - the same referring to the medium level, and $\mu_{3}$-the same referring to the high level. The number of levels $(m=3$ : low, medium, and high), as in the case of Comp_1-Comp_4 competencies, was determined based on differences in the values of the integral competency indicator at these levels that are statistically significant in terms of the $t$-criterion at $p=0.05$.

With regard to the average value of the integral competency assessed during the experiment, $13 \%$ of the second year students had a high level of integral competency $\left(\mu_{3}=1\right)$ and an intermediate level between medium and high levels, with a greater probability of high level $\left(\mu_{3} \geq 0.5\right), 68 \%$ of them having a medium level $\left(\mu_{2} \geq 0.5, \mu_{2}=1\right.$ or $\left.\mu_{3}<0.5\right)$, and $19 \%$ having a low level $\left(\mu_{1}=1\right.$ or $\left.\mu_{2}<0.5\right)$. The following values were observed for the third year students: $20 \%$ showed a high level $\left(\mu_{3} \geq 0.5\right.$ or $\left.\mu_{3}=1\right), 68 \%$ demonstrated a medium level $\left(\mu_{2} \geq 0.5, \mu_{2}=1\right.$ or $\left.\mu_{3}<0.5\right)$, and $12 \%$-a low level $\left(\mu_{1}=1\right.$ or $\left.\mu_{2}<0.5\right)$. The fourth year students had these integral competency levels: $22 \%$ showed a high level $\left(\mu_{3} \geq 0.5\right.$ or $\left.\mu_{3}=1\right), 71 \%$ having a medium level $\left(\mu_{2} \geq 0.5, \mu_{2}=1\right.$ or $\left.\mu_{3}<0.5\right)$, and $7 \%$-a low level $\left(\mu_{1}=1\right.$ or $\left.\mu_{2}<0.5\right)$ (Table 3$)$.

Table 3. The integral level of students' professional competency formedness (in \% of the total number of students in the course).

\begin{tabular}{cccccccc}
\hline & \multicolumn{8}{c}{ Level of Integral Competency, \% } \\
\cline { 2 - 7 } Course & Low & $\begin{array}{c}\text { An Intermediate Level } \\
\text { between Low and } \\
\text { Medium Levels }\end{array}$ & Medium & $\begin{array}{c}\text { An Intermediate Level } \\
\text { between Medium and } \\
\text { High Levels }\end{array}$ & High \\
\hline & $\mu_{1}=1$ & $\mu_{2}<0.5$ & $\mu_{2} \geq 0.5$ & $\mu_{2}=1$ & $\mu_{3}<0.5$ & $\mu_{3} \geq 0.5$ & $\mu_{3}=1$ \\
3 & 8 & 11 & 28 & 27 & 13 & 11 & 2 \\
4 & 3 & 9 & 15 & 32 & 21 & 16 & 4 \\
\hline
\end{tabular}

The impact of the distance-education forms on the value of integral competency is described using the constructed models (Table 4).

Proceeding from the presented system of models describing the impact of various distance-education forms, measured in percentage, on the level of integral competency, the criterion Int $\rightarrow$ max (provided $\rho \mathrm{A}+\rho \mathrm{B}+\rho \mathrm{C}+\rho \mathrm{D}+\rho \mathrm{E}+\rho \mathrm{F}=1$ ) is fulfilled with the following distance learning structure: $\rho \mathrm{A}=0.54, \rho \mathrm{B}=0, \rho \mathrm{C}=0.15, \rho \mathrm{D}=0.14, \rho \mathrm{E}=0.06, \rho \mathrm{F}=0.11$. The reliability of the results is confirmed by a sufficient sample, coefficients of determination $\left(R^{2} \rightarrow 1\right)$, and Fisher's F-criterion, whose calculated values exceed the tabular figures. 
Table 4. Models of the distance-learning structure impact (indicators $\rho \mathrm{A}-\rho \mathrm{F}$ ) on the level students' integral competency formedness.

\begin{tabular}{ccc}
\hline Model & \multicolumn{2}{c}{ Model Adequacy Indicators } \\
\cline { 2 - 3 } & $\begin{array}{c}\text { Coefficient of } \\
\text { Determination } \boldsymbol{( R}^{\mathbf{2}} \mathbf{)}\end{array}$ & $\begin{array}{c}\text { Fisher's } \\
\text { F-Criterion }\end{array}$ \\
\hline Int $=-2.4405 \times \rho A^{2}+3.2855 \times \rho A-0.2321$ & 0.91 & 57.14 \\
Int $=-1.6613 \times \rho B^{2}+0.6096 \times \rho B+0.909$ & 0.89 & 30.61 \\
Int $=-2.1602 \times \rho C^{2}+1.2702 \times \rho C+0.7679$ & 0.92 & 69.43 \\
Int $=-1.1396 \times \rho D^{2}+0.9479 \times \rho D+0.7502$ & 0.94 & 84.11 \\
Int $=2.3064 \times \rho E^{3}-4.1706 \times \rho E^{2}+1.1003 \times \rho E+0.8749$ & 0.90 & 55.07 \\
Int $=4.234 \times \rho F^{3}-6.9408 \times \rho F^{2}+2.0207 \times \rho F+0.7827$ & 0.88 & 49.75 \\
\hline
\end{tabular}

Video lessons are the most effective form of distance learning, which should optimally make up $54 \%$ of the total study time within the discipline over a week. The text lectures should amount to $15 \%$ of study time, as well as $14 \%$ devoted to creative tasks, $11 \%$ to situational tasks, and $6 \%$ to computational tasks. It is less effective to use audio lessons than the above methods. The maximization of the level of students' competencies when using audio lessons without taking into account the limitations in the number of academic hours is achieved with a value of $\rho \mathrm{B}=0.18$. However, taking into account time constraints, the use of audio classes is not so effective as other types of classes, which is expressed in a lower marginal increment in the level of competence with an increase in $\rho$ B by 0.01 .

The proposed optimal structure for distance learning was tested among the students participating in this experiment. Teaching lessons according to the optimal structure resulted in the following weekly indicators of integral competency: a high level for $39 \%$ of students of all specialties and years of study $\left(\mu_{3} \geq 0.5\right.$ or $\left.\mu_{3}=1\right)$, a medium level for $58 \%\left(\mu_{2} \geq 0.5, \mu_{2}=1\right.$ or $\left.\mu_{3}<0.5\right)$, and a low level for $3 \%\left(\mu_{1}=1\right.$ or $\left.\mu_{2}<0.5\right)$.

\section{Discussion}

A methodological approach was thus proposed in this study to find the optimal structure of teaching methods and distance-learning techniques for the formation and development of students' professional competencies. This approach was exemplified by the Ural Federal University in Russia. It is based on determining the quality levels of students' professional competencies formedness in the process of distance learning, which in turn, makes it possible to diagnose the effectiveness of the educational process at any time and to accordingly adjust the corresponding teaching techniques. The proposed approach to assessing these competencies provides for an integrated assessment of their components (constructive-computational, diagnostic-designing, communicative-managerial, and constructive-creative competencies) based on their significance and expert assessment thereof. The use of interval-valued fuzzy sets in assessing the level of competencies provides a balanced assessment for all components. It eliminates the possibility that the high values of one component could compensate for the low values of another, a problem that is typical of the integral methods for competency assessment based on additive or multiplicative convolution. The use of fuzzy sets enables us to take into account the probabilistic nature of assigning "disputed" values, which lack $100 \%$ certainty regarding their level, to the adjacent levels.

The absence of statistically significant differences, as assessed by the $t$-criterion in the average level of competencies depending on the week of the experiment, ensures the universality of the optimal model of distance learning, regardless of the discipline topic.

The methodological approach to distance-education improvement is based on the developed non-linear regression models that allow the researchers to assess the effectiveness of each teaching technique for distance learning at any stage of competency formation and any point in the educational process. These models make it possible to assess the totality of using both visual and verbal pedagogical methodologies $[25,26]$. This, in turn, enables the researchers to take into account the students' individual 
characteristics throughout the distance-learning process and to adjust the educational technology in a timely fashion to enhance the formation of professional competencies.

The conclusions obtained from the results of this study can be used to increase the efficiency of distance learning for students in the study of technical disciplines, regardless of the course of study, based on the observance of the proposed optimal ratios of forms of distance learning.

It is also possible to use the very methodology for modeling the optimal structure of distance learning, depending on the forms of education, which can be applied in relation to other specialties and disciplines, with an emphasis on other forms of education. In order to model the influence of a larger number of variants of combinations of forms of education, it is necessary to choose disciplines for the study of which the maximum number of academic hours is allotted. Except in cases where the effectiveness of distance learning in a particular discipline is being investigated. The distribution of the use of various forms of distance learning by academic week is carried out in any form, provided that all the hours allocated for the study of the discipline are distributed. The level of detail may not be a school week, but, for example, a day if the discipline is taught in blocks with a large number of hours per day, or the subject of the discipline. The greater the number of options for combinations of training forms and the hours allocated for each of these combinations, the higher the accuracy of the results obtained.

\section{Conclusions}

Based on this empirical study, the following conclusions can be drawn. The effectiveness of distance-learning methods at universities is one of the main problems in the Russian higher education system on account of the total quarantine due to the COVID-19 pandemic. No single model of the influence of the distance-learning form on the integral level of professional competencies can be described by a linear function. None of the distance-education forms, therefore, ensure the development of a higher level of students' professional competencies through the maximum increase in their share. Thus, it is possible to talk about the presence of an unbalanced system of teaching techniques of distance learning in the Russian university understudy, which provides only an average level of students' competency formedness.

The developed methodological approach made it possible to determine that in the current conditions the use of audio lessons in distance learning is less effective than other teaching techniques. Video lessons are the most effective method of developing professional competencies in the context of distance education. Video lessons should take up $54 \%$ of the total allotted study time each week for a given discipline for a week. Text lectures should take up 15\%, with $14 \%$ devoted to creative tasks, $11 \%$ to situational tasks, and $6 \%$ to design tasks. The identified structure of teaching techniques can significantly enhance the formation of students' professional competencies during practical use in distance learning.

\section{Limitations and Study Forward}

It should be noted that along with the advantages of the developed methodology for optimizing the structure of teaching technologies of distance learning, it is limited in its application in numerous regards. Because of the complexity of implementing the pedagogical experiment, which requires changes in the educational process and active cooperation with teachers, the study was conducted at only one university. This limits the use of the obtained results toward universities in other countries. However, the research on the development of students' professional competencies while studying in various courses and specialties provides evidence that the identified patterns are universal and can be used to optimize distance learning in Russian universities. The proposed experiment also involved monitoring the results of each week of training to form the maximum survey sample. In real conditions, the use of the proposed optimal structure of distance learning may not be accompanied by so much control, which would not affect the level of students' competencies. 
Due to the insignificant activity of external students of the Ural Federal University, it was impossible to attract them to the experiment. This will become the basis for identifying the features of distance-education effectiveness depending on the forms of study in our future scientific research.

The disadvantage of the distance learning use is that due to the lack of teachers' necessary distance work experience; problems with establishing contact with students; students' perception of this education form is not serious enough; a significant degree of students' relaxation at home; the inability to obtain the prompt answers to the clarifying questions in the lesson course; the lack of team communication; and the level of competence suffers in comparison with the traditional education form. However, this factor was not reflected in this study results, as the experiment was conducted exclusively among the distance-learning students. Therefore, the competence levels in the use of different distance-learning forms are comparable, which ensures the objectivity of the results obtained and the possibility to use the proposed model to improve distance-learning effectiveness.

Another distance-learning problem is the assessment of competencies, as the students cannot perform the tasks on their own, using the Internet, or other assistive means. The problem of the evaluation during the experiment in this study has been minimized due to the fact that non-stereotypical tasks are proposed for the control, whose fulfillment requires certain knowledge and skills to apply it. In addition, each task fulfillment is regulated in time.

Author Contributions: Conceptualization, V.P.; data curation, Z.G. and O.D.; formal analysis, Z.G. and N.K.; investigation, Z.G., V.P., and O.D.; methodology, N.K. and N.N.; project administration, N.N.; validation, Z.G. and E.L.; writing-review and editing, E.L. and S.S. All authors have read and agreed to the published version of the manuscript.

Funding: This research received no external funding.

Conflicts of Interest: The author declares no conflict of interest.

\section{Appendix A}

Schedules for Conducting an Experiment to Improve the Distance-Learning Effectiveness at the University.

Table A1. Schedule for conducting an experiment to improve the distance-learning effectiveness at the university: a case study of learning the discipline "Theoretical Foundations of Electrical Engineering".

\begin{tabular}{cccccccc}
\hline \multirow{2}{*}{$\begin{array}{c}\text { Indexing Number of the } \\
\text { Experiment Week }\end{array}$} & \multicolumn{6}{c}{ Percentage of the Distance-Education Forms $(\rho)$} & \multirow{2}{*}{$\boldsymbol{\Sigma} \rho$} \\
\cline { 2 - 6 } & A & B & C & D & E & F & \\
\hline 1 & - & 0.1 & - & 0.9 & - & - & 1 \\
2 & - & 0.2 & 0.8 & - & - & - & 1 \\
3 & - & 0.3 & - & - & - & 0.7 & 1 \\
4 & - & 0.4 & - & - & - & 0.6 & 1 \\
5 & - & - & 0.3 & - & 0.7 & - & 1 \\
6 & - & - & - & 0.2 & - & 0.8 & 1 \\
7 & - & - & - & 0.5 & - & 0.5 & 1 \\
8 & - & - & 0.7 & - & - & 0.3 & 1 \\
9 & - & - & - & 0.8 & 0.2 & - & 1 \\
10 & 0.1 & - & - & - & - & 0.9 & 1 \\
11 & 0.2 & - & - & - & 0.8 & - & 1 \\
12 & 0.3 & - & - & 0.7 & - & - & 1 \\
13 & 0.4 & - & - & 0.6 & - & - & 1 \\
14 & 0.5 & 0.5 & - & - & - & - & 1 \\
15 & - & - & 0.6 & 0.4 & - & - & 1 \\
16 & 0.7 & - & - & - & 0.3 & - & 1 \\
\hline
\end{tabular}


Table A1. Cont.

\begin{tabular}{cccccccc}
\hline \multirow{2}{*}{$\begin{array}{c}\text { Indexing Number of the } \\
\text { Experiment Week }\end{array}$} & \multicolumn{6}{c}{ Percentage of the Distance-Education Forms $(\rho)$} & \multirow{2}{*}{$\boldsymbol{\Sigma} \rho$} \\
\cline { 2 - 6 } & A & B & C & D & E & F & \\
\hline 17 & 0.8 & - & - & - & - & 0.2 & 1 \\
18 & - & - & 0.1 & - & 0.9 & - & 1 \\
19 & - & 0.6 & - & - & 0.4 & - & 1 \\
20 & - & 0.7 & - & 0.3 & - & - & 1 \\
21 & - & 0.8 & 0.2 & - & - & - & 1 \\
22 & - & 0.9 & - & - & - & 0.1 & 1 \\
23 & - & - & - & - & 0.6 & 0.4 & 1 \\
24 & 0.6 & - & 0.4 & - & - & - & 1 \\
25 & 0.9 & - & - & - & 0.1 & - & 1 \\
26 & - & - & 0.5 & - & 0.5 & - & 1 \\
27 & - & - & 0.9 & 0.1 & - & - & 1 \\
\hline
\end{tabular}

Table A2. Schedule for conducting an experiment to improve the distance-learning effectiveness at the university: a case study of learning the discipline "Electric Machines in the Electrical Power-Generation Industry".

\begin{tabular}{|c|c|c|c|c|c|c|c|}
\hline \multirow{2}{*}{$\begin{array}{l}\text { Indexing Number of the } \\
\text { Experiment Week }\end{array}$} & \multicolumn{6}{|c|}{ Percentage of the Distance-Education Forms $(\rho)$} & \multirow{2}{*}{$\Sigma \rho$} \\
\hline & A & B & $\mathrm{C}$ & $\mathbf{D}$ & $\mathbf{E}$ & F & \\
\hline 1 & - & - & 0.1 & 0.9 & - & - & 1 \\
\hline 2 & - & 0.1 & - & - & 0.9 & - & 1 \\
\hline 3 & - & - & 0.2 & - & - & 0.8 & 1 \\
\hline 4 & - & - & - & 0.8 & - & 0.2 & 1 \\
\hline 5 & - & - & - & 0.6 & 0.4 & - & 1 \\
\hline 6 & - & - & 0.3 & - & 0.7 & - & 1 \\
\hline 7 & - & - & - & - & 0.1 & 0.9 & 1 \\
\hline 8 & - & - & 0.6 & - & - & 0.4 & 1 \\
\hline 9 & - & 0.8 & - & 0.2 & - & - & 1 \\
\hline 10 & - & 0.2 & - & - & 0.8 & - & 1 \\
\hline 11 & - & - & 0.5 & 0.5 & - & - & 1 \\
\hline 12 & - & 0.3 & - & - & - & 0.7 & 1 \\
\hline 13 & - & 0.7 & - & - & 0.3 & - & 1 \\
\hline 14 & - & 0.4 & - & - & - & 0.6 & 1 \\
\hline 15 & - & - & 0.9 & 0.1 & - & - & 1 \\
\hline 16 & - & 0.5 & - & - & 0.5 & - & 1 \\
\hline 17 & - & - & 0.7 & - & - & 0.3 & 1 \\
\hline 18 & - & 0.6 & - & 0.4 & - & - & 1 \\
\hline 19 & 0.1 & 0.9 & - & - & - & - & 1 \\
\hline 20 & 0.2 & - & 0.8 & - & - & - & 1 \\
\hline 21 & 0.3 & - & - & 0.7 & - & - & 1 \\
\hline 22 & 0.4 & - & - & - & 0.6 & - & 1 \\
\hline 23 & 0.5 & - & - & - & - & 0.5 & 1 \\
\hline 24 & 0.6 & - & 0.4 & - & - & - & 1 \\
\hline 25 & 0.7 & - & - & 0.3 & - & - & 1 \\
\hline 26 & 0.8 & - & - & - & 0.2 & - & 1 \\
\hline 27 & 0.9 & - & - & - & - & 0.1 & 1 \\
\hline
\end{tabular}


Table A3. Schedule for conducting an experiment to improve the distance-learning effectiveness at the university: a case study of learning the discipline "Protection and Automation of Electrical Power Systems".

\begin{tabular}{|c|c|c|c|c|c|c|c|}
\hline \multirow{2}{*}{$\begin{array}{l}\text { Indexing Number of the } \\
\text { Experiment Week }\end{array}$} & \multicolumn{6}{|c|}{ Percentage of the Distance-Education Forms $(\rho)$} & \multirow{2}{*}{$\Sigma \rho$} \\
\hline & A & B & $\mathrm{C}$ & $\mathbf{D}$ & $\mathbf{E}$ & $\mathbf{F}$ & \\
\hline 1 & - & - & 0.3 & 0.7 & - & - & 1 \\
\hline 2 & - & 0.5 & - & 0.5 & - & - & 1 \\
\hline 3 & - & - & 0.4 & - & 0.6 & - & 1 \\
\hline 4 & 0.1 & - & - & 0.9 & - & - & 1 \\
\hline 5 & 0.2 & - & 0.8 & - & - & - & 1 \\
\hline 6 & 0.3 & - & - & - & 0.7 & - & 1 \\
\hline 7 & 0.4 & 0.6 & - & - & - & - & 1 \\
\hline 8 & 0.5 & - & - & - & - & 0.5 & 1 \\
\hline 9 & 0.6 & - & - & - & 0.4 & - & 1 \\
\hline 10 & 0.7 & - & - & 0.3 & - & - & 1 \\
\hline 11 & 0.8 & - & 0.2 & - & - & - & 1 \\
\hline 12 & 0.9 & 0.1 & - & - & - & - & 1 \\
\hline 13 & - & - & 0.5 & - & 0.5 & - & 1 \\
\hline 14 & - & 0.4 & 0.6 & - & - & - & 1 \\
\hline 15 & - & - & - & 0.1 & 0.9 & - & 1 \\
\hline 16 & - & - & - & - & 0.8 & 0.2 & 1 \\
\hline 17 & - & 0.2 & - & 0.8 & - & - & 1 \\
\hline 18 & - & - & - & 0.4 & - & 0.6 & 1 \\
\hline 19 & - & - & 0.7 & - & - & 0.3 & 1 \\
\hline 20 & - & 0.3 & - & - & - & 0.7 & 1 \\
\hline 21 & - & - & - & 0.6 & - & 0.4 & 1 \\
\hline 22 & - & - & - & - & 0.2 & 0.8 & 1 \\
\hline 23 & - & 0.7 & - & - & 0.3 & - & 1 \\
\hline 24 & - & - & - & - & 0.1 & 0.9 & 1 \\
\hline 25 & - & 0.9 & 0.1 & - & - & - & 1 \\
\hline 26 & - & - & 0.9 & - & - & 0.1 & 1 \\
\hline 27 & - & 0.8 & - & 0.2 & - & - & 1 \\
\hline
\end{tabular}

Table A4. Schedule for conducting an experiment to improve the distance-learning effectiveness at the university: a case study of learning the discipline "Stability Theory".

\begin{tabular}{cccccccc}
\hline \multirow{2}{*}{$\begin{array}{c}\text { Indexing Number of the } \\
\text { Experiment Week }\end{array}$} & \multicolumn{6}{c}{ Percentage of the Distance-Education Forms $(\rho)$} & \multirow{2}{*}{$\boldsymbol{\Sigma} \rho$} \\
\cline { 2 - 6 } & A & B & C & D & E & F & \\
\hline 1 & - & - & - & 0.8 & 0.2 & - & 1 \\
2 & - & - & - & 0.9 & 0.1 & - & 1 \\
3 & - & 0.9 & - & 0.1 & - & - & 1 \\
4 & - & - & 0.8 & - & - & 0.2 & 1 \\
5 & - & 0.6 & - & - & 0.4 & - & 1 \\
6 & 0.9 & - & 0.1 & - & - & - & 1 \\
7 & 0.8 & - & - & 0.2 & - & - & 1 \\
8 & 0.7 & - & - & - & 0.3 & - & 1 \\
9 & 0.6 & - & - & - & - & 0.4 & 1 \\
10 & - & - & 0.5 & 0.5 & - & - & 1 \\
11 & - & 0.5 & - & - & - & 0.5 & 1 \\
12 & - & 0.7 & - & - & - & 0.3 & 1 \\
13 & - & - & - & 0.4 & 0.6 & - & 1 \\
14 & - & 0.4 & 0.6 & - & - & - & 1 \\
15 & - & - & - & 0.3 & - & 0.7 & 1 \\
\hline
\end{tabular}


Table A4. Cont.

\begin{tabular}{cccccccc}
\hline \multirow{2}{*}{$\begin{array}{c}\text { Indexing Number of the } \\
\text { Experiment Week }\end{array}$} & \multicolumn{9}{c}{ Percentage of the Distance-Education Forms $(\rho)$} & \multirow{2}{*}{$\boldsymbol{\Sigma} \rho$} \\
\cline { 2 - 6 } 16 & A & B & C & D & E & F & \\
\hline 17 & - & - & 0.9 & - & - & 0.1 & 1 \\
18 & - & 0.3 & - & 0.7 & - & - & 1 \\
19 & 0.5 & - & - & - & 0.5 & - & 1 \\
20 & 0.3 & - & - & 0.6 & - & - & 1 \\
21 & 0.2 & 0.8 & - & - & - & - & 1 \\
22 & 0.1 & - & - & - & - & 0.9 & 1 \\
23 & - & 0.2 & - & - & - & 0.8 & 1 \\
24 & - & - & 0.2 & - & 0.8 & - & 1 \\
25 & - & 0.1 & - & - & 0.9 & - & 1 \\
26 & - & - & 0.3 & - & 0.7 & - & 1 \\
27 & - & - & 0.4 & - & - & 0.6 & 1 \\
\hline
\end{tabular}

Table A5. Schedule for conducting an experiment to improve the distance-learning effectiveness at the university: a case study of learning the discipline "Theoretical Mechanics".

\begin{tabular}{|c|c|c|c|c|c|c|c|}
\hline \multirow{2}{*}{$\begin{array}{l}\text { Indexing Number of the } \\
\text { Experiment Week }\end{array}$} & \multicolumn{6}{|c|}{ Percentage of the Distance-Education Forms $(\rho)$} & \multirow{2}{*}{$\Sigma \rho$} \\
\hline & A & B & C & D & E & $F$ & \\
\hline 1 & - & 0.2 & - & 0.8 & - & - & 1 \\
\hline 2 & - & - & 0.6 & - & - & 0.4 & 1 \\
\hline 3 & - & - & 0.2 & - & - & 0.8 & 1 \\
\hline 4 & - & 0.3 & 0.7 & - & - & - & 1 \\
\hline 5 & - & - & - & 0.3 & 0.7 & - & 1 \\
\hline 6 & - & - & - & 0.5 & 0.5 & - & 1 \\
\hline 7 & 0.9 & - & - & - & 0.1 & - & 1 \\
\hline 8 & 0.8 & - & - & 0.2 & - & - & 1 \\
\hline 9 & - & 0.5 & 0.5 & - & - & - & 1 \\
\hline 10 & - & 0.1 & - & - & 0.9 & - & 1 \\
\hline 11 & - & - & - & 0.7 & - & 0.3 & 1 \\
\hline 12 & - & - & - & - & 0.3 & 0.7 & 1 \\
\hline 13 & 0.7 & - & 0.3 & - & - & - & 1 \\
\hline 14 & 0.6 & 0.4 & - & - & - & - & 1 \\
\hline 15 & 0.5 & - & - & - & - & 0.5 & 1 \\
\hline 16 & 0.4 & - & - & 0.6 & - & - & 1 \\
\hline 17 & 0.3 & 0.7 & - & - & - & - & 1 \\
\hline 18 & - & - & 0.4 & - & 0.6 & - & 1 \\
\hline 19 & - & 0.6 & - & 0.4 & - & - & 1 \\
\hline 20 & - & - & - & - & 0.8 & 0.2 & 1 \\
\hline 21 & - & - & 0.9 & 0.1 & - & - & 1 \\
\hline 22 & - & - & - & - & 0.4 & 0.6 & 1 \\
\hline 23 & - & 0.9 & 0.1 & - & - & - & 1 \\
\hline 24 & 0.2 & - & 0.8 & - & - & - & 1 \\
\hline 25 & 0.1 & - & - & - & - & 0.9 & 1 \\
\hline 26 & - & - & - & 0.9 & - & 0.1 & 1 \\
\hline 27 & - & 0.8 & - & - & 0.2 & - & 1 \\
\hline
\end{tabular}


Table A6. Schedule for conducting an experiment to improve the distance-learning effectiveness at the university: a case study of learning the discipline "Metallurgical Machines and Equipment".

\begin{tabular}{|c|c|c|c|c|c|c|c|}
\hline \multirow{2}{*}{$\begin{array}{l}\text { Indexing Number of the } \\
\text { Experiment Week }\end{array}$} & \multicolumn{6}{|c|}{ Percentage of the Distance-Education Forms $(\rho)$} & \multirow{2}{*}{$\Sigma \rho$} \\
\hline & A & B & $\mathrm{C}$ & $\mathbf{D}$ & $\mathbf{E}$ & F & \\
\hline 1 & - & 0.5 & 0.5 & - & - & - & 1 \\
\hline 2 & - & - & 0.2 & 0.8 & - & - & 1 \\
\hline 3 & - & 0.6 & - & - & - & 0.4 & 1 \\
\hline 4 & - & - & 0.9 & 0.1 & - & - & 1 \\
\hline 5 & - & - & - & 0.9 & 0.1 & - & 1 \\
\hline 6 & 0.9 & 0.1 & - & - & - & - & 1 \\
\hline 7 & - & - & - & - & 0.3 & 0.7 & 1 \\
\hline 8 & - & 0.7 & - & 0.3 & - & - & 1 \\
\hline 9 & - & - & - & - & 0.5 & 0.5 & 1 \\
\hline 10 & - & - & 0.8 & - & - & 0.2 & 1 \\
\hline 11 & - & - & - & 0.4 & - & 0.6 & 1 \\
\hline 12 & - & 0.4 & - & - & 0.6 & - & 1 \\
\hline 13 & 0.8 & - & - & - & 0.2 & - & 1 \\
\hline 14 & - & - & 0.7 & - & - & 0.3 & 1 \\
\hline 15 & 0.7 & - & 0.3 & - & - & - & 1 \\
\hline 16 & - & 0.9 & - & - & - & 0.1 & 1 \\
\hline 17 & 0.6 & - & 0.4 & - & - & - & 1 \\
\hline 18 & - & 0.8 & - & 0.2 & - & - & 1 \\
\hline 19 & 0.5 & - & - & 0.5 & - & - & 1 \\
\hline 20 & - & 0.2 & - & - & - & 0.8 & 1 \\
\hline 21 & - & - & - & 0.6 & 0.4 & - & 1 \\
\hline 22 & - & 0.3 & - & 0.7 & - & - & 1 \\
\hline 23 & 0.3 & - & - & - & 0.7 & - & 1 \\
\hline 24 & - & - & 0.1 & - & 0.9 & - & 1 \\
\hline 25 & 0.2 & - & - & - & 0.8 & - & 1 \\
\hline 26 & 0.4 & - & 0.6 & - & - & - & 1 \\
\hline 27 & 0.1 & - & - & - & - & 0.9 & 1 \\
\hline
\end{tabular}

\section{References}

1. United Nations Educational, Scientific and Cultural Organisation. Education for All 2000-2015: Achievements and Challenges. Available online: https://unesdoc.unesco.org/ark:/48223/pf0000232205 (accessed on 24 April 2020).

2. United Nations Educational, Scientific and Cultural Organisation. Learning throughout Life: Challenges for the Twenty-First Century. Available online: https://unesdoc.unesco.org/ark:/48223/pf0000127540 (accessed on 24 April 2020).

3. Kulnazarova, A.; Ydesen, C. UNESCO without Borders. Educational Campaigns for International Understanding; Routledge: London, UK, 2018.

4. Radif, M.; Mohammed, N.A. Computer science teacher's perception and needs towards E-learning in Iraq. J. Southwest Jiaotong Univ. 2019, 54. [CrossRef]

5. Caliskan, S.; Suzek, S.; Ozcan, D. Determining student satisfaction in distance education courses. Procedia Comput. Sci. 2017, 120, 529-538. [CrossRef]

6. Alrubaie, S.A.; Alrubaie, M.A.; Hassoon, I.M. The role of activating electronic training in increasing efficiency of training process. J. Southwest Jiaotong Univ. 2020, 55. [CrossRef]

7. Kegeyan, S.E. Distance learning: Its advantages and disadvantages. Int. J. Prof. Sci. 2016, 1, 71-74.

8. Learning House. Online College Students 2018. Comprehensive Data on Demands and Preferences. Available online: https://www.learninghouse.com/knowledge-center/research-reports/ocs2018/ (accessed on 24 April 2020).

9. Zuhairi, A.; Karthikeyan, N.; Priyadarshana, S.T. Supporting students to succeed in open and distance learning in the Open University of Sri Lanka and Universitas Terbuka Indonesia. Asian Assoc. Open Univ. J. 2019, 15, 13-35. [CrossRef] 
10. Qayyum, A.; Zawacki-Richter, O. Open and Distance Education in Australia, Europe and the Americas: National Perspectives in a Digital Age; Springer: Singapore, 2018.

11. Qayyum, A.; Zawacki-Richter, O. The state of open and distance education. In Open and Distance Education in Asia, Africa and the Middle East. SpringerBriefs in Education; Zawacki-Richter, O., Qayyum, A., Eds.; Springer: Singapore, 2019; pp. 125-140.

12. The Ministry of Education of the Russian Federation. National Project "Education". Available online: https://edu.gov.ru/national-project/ (accessed on 24 April 2020).

13. Ministry of Science and Higher Education of the Russian Federation. Order No. 397 "On the Arrangement of Educational Activities in Organizations Implementing Educational Programs of Higher Education and Relevant Additional Professional Programs, in the Context of Preventing the Spread of a New Coronavirus Infection in the Territory of the Russian Federation". Available online: https://www.minobrnauki.gov.ru/ common/upload/library/2020/03/main/397.pdf (accessed on 24 April 2020).

14. Ministry of Science and Higher Education of the Russian Federation. Order No. 484 “On Measures to Implement the Decree of the President of the Russian Federation No. 206 of 25 March 2020 "On the Announcement of Non-Working Days in the Russian Federation"'". Available online: https://minobrnauki. gov.ru/common/upload/library/2020/03/main/484.pdf.pdf.pdf (accessed on 24 April 2020).

15. Ministry of Science and Higher Education of the Russian Federation. Order No. 634 "On Amendments to the Order of the Ministry of Science and Higher Education of the Russian Federation No. 545 Dated April 2, 2020 “On Measures for the Implementation of the Presidential Decree No. 239 of April 2, 2020 “On Measures for Ensuring Sanitary and Epidemiological Welfare of the Population in the Russian Federation in Connection with the Spread of a New Coronavirus Infection (COVID-19)" by Organizations Subordinated to the Ministry of Science and Higher Education of the Russian Federation"'". Available online: https: //minobrnauki.gov.ru/common/upload/library/2020/04/main/Dokument_1.pdf (accessed on 24 April 2020).

16. Podtserob, M.; Bershidsky, M.; Petrova, Y. Russian Universities Report on the Transition to Online Education. Vedomosti. Available online: https://www.vedomosti.ru/management/articles/2020/03/25/826230-rossiiskievuzi (accessed on 24 April 2020).

17. Shapovalova, S. Why Is Distance Learning Called the "Imperative of Our Time"? Regnum. Available online: https://regnum.ru/news/innovatio/2924037.html (accessed on 24 April 2020).

18. Committee on Education and Science. Draft Federal Law No. 607448-7 “On Amendments to the Federal Law "On Education in the Russian Federation" as Regards Improving the Practical Training of Students"; 2018. Available online: https://elibrary.ru/item.asp?id=41863282 (accessed on 24 April 2020).

19. Education Navigator. Coronavirus "Exposed" All the Problems of Distance Learning. Available online: https://fulledu.ru/articles/1621_koronavirus-obnazhil-vse-problemy-distancionnogo.html (accessed on 24 April 2020).

20. Wilkinson, B.; Leis, H. This Research Can Help Organizations Plan for Different COVID-19 Scenarios. World Economic Forum. Available online: https:/www.weforum.org/agenda/2020/04/research-can-helporganizations-plan-for-different-covid-19-scenarios/ (accessed on 24 April 2020).

21. Leung, K.; Wu, J.T.; Liu, D.; Leung, G.M. First-wave COVID-19 transmissibility and severity in China outside Hubei after control measures, and second-wave scenario planning: A modelling impact assessment. Lancet 2020, 395, 1382-1393. [CrossRef]

22. United Nations Office for the Coordination of Humanitarian Affairs. COVID-19: Scenarios, Possible Global Humanitarian Developments over the Next Six Months. Available online: https://reliefweb.int/report/world/ covid-19-scenarios-possible-global-humanitarian-developments-over-next-six-months-april (accessed on 24 April 2020).

23. Moore, K.A.; Lipsitch, M.; Barry, J.M.; Osterholm, M.T. COVID-19: The CIDRAP Viewpoint. Part 1: The Future of the COVID-19 Pandemic: Lessons Learned from Pandemic Influenza. University of Minnesota. Available online: https://www.cidrap.umn.edu/sites/default/files/public/downloads/cidrapcovid19-viewpoint-part1_0.pdf (accessed on 24 April 2020).

24. Kleczkowski, A.; Kao, R.R. Scenarios for How the COVID-19 Pandemic Might End, and Why We Might Have to Live with It for Years to Come. Newsweek. Available online: https://www.newsweek.com/scenarioshow-covid-19-pandemic-ends-1494374 (accessed on 24 April 2020).

25. Arias, J.J.; Swinton, J.; Anderson, K. Online vs. face-to-face: A comparison of student outcomes with random assignment. e-J. Bus. Educ. Scholarsh. Teach. 2018, 12, 1-23. 
26. Alhih, M.; Ossiannilsson, E.; Berigel, M. Levels of interaction provided by online distance education models. EURASIA J. Math. Sci. Technol. Educ. 2017, 13, 2733-2748. [CrossRef]

27. Xu, L.; Yang, Q. Modeling and analysis on teacher-student relationship. Discrete Dyn. Nat. Soc. 2019, 2019, 5481926. [CrossRef] [PubMed]

28. Shah, S.I.; Shahjehan, A.; Afsar, B.; Afridi, S.A.; Saeed, B.B. The dynamics of leader technical competence, subordinate learning, and innovative work behaviors in high-tech, knowledge-based industry. Econ. Res. 2020, 33, 623-638. [CrossRef]

29. Smith, B.; Hernandez, M.; Gordon, J. Competency-Based Learning. Available online: https://apps.dtic.mil/ dtic/tr/fulltext/u2/1077111.pdf (accessed on 24 April 2020).

30. Herppich, S.; Praetorius, A.-K.; Förster, N.; Glogger-Frey, I.; Karst, K.; Leutner, D.; Behrmann, L.; Böhmer, M.; Ufer, S.; Klug, J.; et al. Teachers' assessment competence: Integrating knowledge-, process-, and product-oriented approaches into a competence-oriented conceptual model. Teach. Teach. Educ. 2018, 76, 181-193. [CrossRef]

31. Krawczak, M.; Szkatuła, G. On matching of intuitionistic fuzzy sets. Inf. Sci. 2020, 517, 254-274. [CrossRef]

Publisher's Note: MDPI stays neutral with regard to jurisdictional claims in published maps and institutional affiliations.

(C) 2020 by the authors. Licensee MDPI, Basel, Switzerland. This article is an open access article distributed under the terms and conditions of the Creative Commons Attribution (CC BY) license (http://creativecommons.org/licenses/by/4.0/). 